\title{
CERTAS CANÇÕES: Teologia e literatura na música brasileira
}

\author{
CeRTAIN SONGS: \\ Theology and literature in brazilian music
}

Antônio Manzatto*

\section{RESUMO}

É certo que música não é literatura e as canções não são simplesmente poesias musicadas. No entanto seria possível, como para as relações entre teologia e literatura, estabelecer relações entre teologia e canções? O relato a seguir exemplifica tal possiblidade quando analisa, antropológica e teologicamente, uma canção brasileira. O objetivo é demonstrar que há uma possiblidade de aproximação entre a reflexão teológica e a interpretação, ao menos, da letra de canções que falam ao coração das pessoas.

Palavras-chave: Teologia e literatura. Antropologia teológica. Canções. Música Popular Brasileira. Cultura brasileira.

\section{ABSTRACT}

It is true that music is not literature, and the songs are not just poetry set to music. However, it would be possible, as for the relationship between theology and literature, establish relationships between theology and songs? The study below illustrates this possibility when analyzing, anthropologically and theologically, a Brazilian song. The objective is to demonstrate that there is a possibility of rapprochement between theological reflection and interpretation, at least, the words of the songs that speak to people's hearts.

Keywords: Theology and Literature. Theological anthropology. Songs. Brazilian music. Brazilian culture.

\footnotetext{
* Professor da PUC/SP.
}

\begin{tabular}{|l|l|l|l|l|l|}
\hline Teocomunicação & Porto Alegre & v. 45 & n. 1 & p. 24-37 & jan.-abr. 2015 \\
\hline
\end{tabular}




\section{Introdução}

O presente artigo apresenta a motivação teológica e pastoral de uma experiência vivida na aproximação entre música e teologia em uma emissão radiofônica. Sob esta forma, relata uma experiência que se tem mostrado pertinente. Emissões religiosas, no mais das vezes, têm características cultuais ou catequéticas proporcionadas pelos próprios ritos religiosos. É o que vemos nos meios de comunicação atualmente, e isto tem seu valor próprio. Mas constitui como que um diálogo entre crentes que acontece no interior da comunidade confessante e que, não raro, assume por isso forma apologética. $\mathrm{O}$ desafio que permanece é o de dialogar com o diferente, de alcançar outros auditórios ou espaços de encontro com realidades que não são aquelas especificamente religiosas. Isto é o que se tenta com uma emissão radiofônica que contempla canções que podem fazer pensar na vida, mas também nos conteúdos mesmos da teologia. A experiência de aproximação com a literatura, também ela formadora de cultura como a música, pode ajudar na elaboração de um procedimento que permita que se faça teologia a partir do horizonte de canções não religiosas.

É verdade que música não é literatura. A maneira de aproximar-se de uma e outra são diferentes, embora haja pontos comuns entre elas. A música releva a beleza da melodia captada pela audição; sua sonoridade lhe é essencial e não é raro que ali, e somente ali, se julgue de sua beleza. Afinal, existem muitas músicas que não são cantadas, que não possuem letra, que não são partes de uma canção. Por isso, muitas vezes, ao se pensar na aproximação entre música e teologia se pensa no mundo da liturgia, onde a música tem seu lugar de destaque porque formata um ambiente celebrativo bastante interessante e até mesmo apropriado para a afirmação da fé (CNBB, 2002). Também a chamada Música Popular Brasileira conhece ritmos, músicas e melodias que não são cantadas, que não possuem letra. Dentro desta compreensão, a forma de aproximar a música da teologia será diferente e exigirá outros recursos que aqueles normalmente utilizados no diálogo entre literatura e teologia.

Mas, sem esquecer a importância da sonoridade, uma canção terá uma letra, palavras que, conjugadas, constituirão um significado. Ela é a parte "dita" da canção, será cantada e apontará para uma história contada. Jacques Brel dizia que cantaria enquanto tivesse histórias para contar. A letra da canção será uma forma de contar uma história através de seu casamento com uma melodia. Normalmente uma letra se insere 
em uma melodia; é raro que uma música contenha várias letras, assim como uma letra seja cantada de várias maneiras. Sobretudo no horizonte popular, uma letra tem a ver com uma melodia e, juntas, formam uma canção.

A letra da canção não será, simplesmente, uma poesia musicada. Por isso, a rigor, seu estudo, sua análise e sua aproximação com a teologia deverá ter em vista o horizonte musical, até porque as palavras, muitas vezes, são escolhidas em função da melodia com a qual a letra formará um todo. Mas, de alguma forma, as letras das canções formam uma realidade em si, em certa autonomia. Contam uma história que, se não pode desligar-se de sua melodia, também não depende exclusivamente dela para ter sentido. Ao mesmo tempo em que letra e melodia formam um todo, elas também tem sentido se tomadas separadamente. Por isso melodias podem ser executadas sem suas letras, e estas, poderão ser tomadas independentemente de sua musicalidade.

É neste sentido que canções são aproximadas da teologia a partir das chaves do diálogo desta com a literatura. Tomam-se as letras das canções como se fossem poesia e, pelo viés da literatura, se faz com que dialoguem com a teologia. ${ }^{1} \mathrm{O}$ procedimento parece válido, mesmo se manco. O diálogo da teologia com a sonoridade ainda resta todo a ser feito, e não será este o objetivo do presente texto, senão apenas lembrar qual o caminho resta a ser percorrido. A obra de Calvani (1998), que aproxima a teologia da Música Popular Brasileira, segue este procedimento. Como disse, ele é válido porque o horizonte do estudo permanece sendo o da análise das letras das canções. Se a canção não é simples poesia musicada, ela, de alguma maneira, permanece sendo poesia. Tomada por este viés, é passível de aproximação com a teologia pelos mesmos procedimentos que aproximam poesia e teologia.

$\mathrm{Na}$ aproximação entre teologia e poesia, o trabalho de Alex Villas Boas (2011) se constitui em marco obrigatório de passagem. A poesia tem natureza própria e sua análise requer procedimentos que deem conta disso; porém, ela também é literatura, e talvez o seja em sua forma mais plena e perfeita. A legitimidade de aproximação entre poesia e teologia já está afirmada, assim como métodos que possibilitam seu diálogo com a teologia. Permanece no horizonte, no entanto, o fato de a poesia, sobretudo aquela das canções, ser uma história contada. Há algo

\footnotetext{
1 O procedimento de Amaral, 2013, quer ser um tanto diferente ao estudar as canções a partir da teologia que manifestam de forma explícita.
} 
que se diz através da poesia, mais do que a soma de palavras ou sinais de pontuação. Há significado, sentido, e Villas Boas é feliz ao insistir neste aspecto. Uma poesia não é simples divagação sem nexo. Contar uma história, fazer afirmações, dizer algo, não se resume a maneiras diferentes de narrar. Uma poesia pode não ser uma narração, mas nem por isso deixa de contar uma história. Assim é com as canções. Cada canção, de alguma maneira, conta uma história, faz afirmações, traz à luz um significado. Apresenta uma experiência de vida, e por isso não se ouvem, simplesmente, as canções, mas se as vive. E quando elas são cantadas, trazem à memória e ao pensamento o que lembram e o que significam como experiência vivida por quem as canta (HERRERA, 2013). Há valores afirmados nas canções, inclusive alguns que podem ser cristãos, como a solidariedade, a gratuidade, etc. Por estes motivos, a canção pode interessar à teologia.

\section{Sobre os métodos}

O diálogo entre a canção e a teologia segue, então, os procedimentos já estabelecidos para o relacionamento entre teologia e literatura. Aqui se põe a questão dos métodos e maneiras de realizar tal aproximação. No horizonte atual, os métodos mais utilizados são o antropológico, o de correlação e o da teopoética. Todos poderão ser utilizados para o diálogo da teologia com as canções, até porque, devido às diferenças entre estas, diferenças que vão para além do ritmo, um ou outro método pode ser mais útil, mais fácil ou mais significativo.

O chamado método antropológico (MANZATTO, 1994) é aquele que define o campo da antropologia como terreno comum entre literatura e teologia, o que permite seu encontro e diálogo. Uma e outra falam do humano e, por isso, podem dialogar entre si. O método de correlação, baseado nos pensamentos de Paul Tillich (2005) e de Kuschel (1999), foi estabelecido por Antonio Magalhães (2000) e toma literatura e teologia como dois conjuntos cujos elementos podem se relacionar a partir da temática comum, permitindo então o diálogo entre elas. A teopoética (MANZATTO, 2010) prefere relacioná-las pela temática ou forma que adotam para sua constituição, até mesmo pela comparação entre uma e outra. Na Argentina, o Seminário Interdisciplinar Permanente de Literatura, Estética e Teologia prefere uma aproximação entre poesia e mística, sobretudo pelo caminho da estética de Balthasar (PALUMBO, 2014). Variados métodos, repita-se, podem ser utilizados para aproximar 
a teologia das canções, ou das letras das canções, tomando-as como peças literárias; o método mais adequado será aquele que mais facilitar o estudo daquela canção ou aquele que melhor ajudar a compreender (RICOEUR, 1986) a história que ela conta e o que ela diz.

Não exatamente ligada à questão dos métodos, podemos encontrar o problema dos procedimentos. Afinal, por serem canções, ainda que olhando única ou prioritariamente para sua letra, o rádio é lugar mais apto que o texto para que se realize o encontro da canção e da teologia. A sonoridade pode ser ali captada e mesmo que não seja elemento constituinte da reflexão que se segue, é elemento da formação da canção. Daí o interesse em relatar a experiência radiofônica vivida. Ouvir a canção com sua letra musicada e, então, realizar uma reflexão teológica com ambições de alcance pastoral, eis o procedimento que aqui se estabelece, ainda que, repita-se, o presente texto não inclua a dimensão sonora.

\section{Perspectiva pastoral}

O diálogo entre a teologia e as canções, quando feito no rádio, vai denunciar um objetivo pastoral evidente. Não se fazem grandes análises de letras de canções, nem elaborados textos de reflexão teológica. Antes, as questões práticas são colocadas em evidência de maneira muito rápida e direta. Até porque, em um programa de rádio, conta muito o tempo da emissão e sua forma de apresentação. O diálogo com o ouvinte precisa ser rápido e direto. Daí a ideia de uma pequena contextualização da canção e o apontamento direto de aspectos interessantes de sua natureza para, em seguida, apontar para um significado teológico com implicações pastorais quase que imediatas. Não se trata propriamente de teologia prática em ação, nem tampouco de "teologia aplicada", mas sim, quase que de maneira parenética, de apontamentos de significados que possam interessar o ouvinte em sua prática religiosa ou em sua maneira de organizar sua vida a partir do horizonte de sua fé.

Claro que isso impõe uma série de limites à reflexão teológica, e é bom estar ciente deles. Contudo ainda se pode considerar pertinente a aventura, até por conta desta finalidade pastoral. Do ponto de vista da estrita teologia, é interessante uma demonstração de que a teologia pode nutrir-se de outras realidades que não a simples prática de ritos religiosos. Arejar a teologia com elementos vindos de fora dela pode ajudar a retirá-la da prisão conservadora onde foi colocada em tempos não tão 
distantes. Grandes avanços da prática teológica se fizeram exatamente quando a teologia se dispôs a perscrutar outros horizontes - a filosofia, a sociologia, a vida prática dos cristãos, a organização da sociedade, as diferentes culturas - e assim por diante. Olhar para o ambiente cultural que é a situação atual, e que foi moldado, também, pelas canções que dizem de uma maneira de ser e existir, e tentar estabelecer com elas um diálogo ou uma aproximação, pode ser interessante não apenas para a teologia, mas também para a vivência cristã.

Por isso não se trata de analisar qualquer canção, ou de se render aos interesses comerciais que as situam nas paradas de sucesso. Trata-se, antes, de olhar para canções significativas para a formação da alma brasileira e que, claro, tiveram um reconhecimento popular que as faz, ainda hoje, serem lembradas e cantadas. Por outro lado, a seleção musical não poderá responder a interesses meramente moralistas, utilizandose de canções para dizer algo que se julga importante seja dito. Uma canção não é simplesmente outra maneira de se dizer aquilo que se quer dizer em conceitos ou pregações. A honestidade na seleção das canções será marca da exigência de seriedade do programa de rádio que, sem deixar de ser forma de entretenimento, quer ser exortativo e, talvez, catequético, porque pastoral. Não se faz o estudo de qualquer canção, mas sim de "certas canções".

\section{A forma do programa}

O primeiro ano de emissão do programa foi marcado por dois modelos de apresentação, mas com um núcleo comum. $\mathrm{O}$ elemento central é a canção a ser cantada e estudada e aquilo que ela diz. Neste sentido o primeiro modelo de apresentação resumiu-se a apresentar uma única canção e executá-la ao menos duas vezes. Além disso, refleti- se sobre o significado da canção e sua relação com a teologia, fazendo com que a execução da canção se repetisse em segundo plano. Era assim possível a quem ouvisse o programa que não apenas cantasse a canção, mas pensasse nas palavras que estava cantando enquanto a reflexão ia sendo feita.

Foi assim que a emissão se realizou durante certo período, com meia hora de duração. Tempo para a execução das canções e a reflexão que se fazia. Contudo foi proposto pela direção da emissora que o programa dobrasse seu tempo de duração, e passasse a ter uma hora inteira. O primeiro pensamento foi, então, o de se refletir sobre duas 
canções, mas isso corria o risco de ser pouco prático, pois uma canção faria com que a outra fosse esquecida. Não seria interessante comentar dois assuntos no mesmo dia, e um mesmo assunto repetido duas vezes não seria conveniente.

Passou-se, então, à elaboração de um segundo modelo de formatação da emissão e que se propunha a valorizar o entretenimento e a diversidade. Guardava-se, como essencial, o modelo de apresentação da canção sobre a qual refletia-se e a isso se acrescentavam outras canções. A canção central, constitutiva da emissão, foi chamada de "Uma canção para pensar"; executava-se esta canção duas vezes e refletia-se sobre ela em dois momentos, sobre o que dizia e sobre seu eventual significado para a religião e a teologia; enquanto se fazia a reflexão, ela era executada em segundo plano, exatamente como no primeiro modelo. Sua execução foi precedida por outra canção, que de alguma forma introduzia o assunto sobre o qual seria realizada a base da emissão, e que por isso foi chamada de "Pra começo de conversa". Sua ligação com a canção central poderia ser temática ou então casual, como o mesmo intérprete, mesmo compositor, mesmo ano de gravação ou outro aspecto que permitisse uma ligação, ainda que superficial com a "canção para pensar". A esta se seguia "Uma canção do lado de lá", que apresentava uma canção internacional que, eventualmente, falava do mesmo tema de reflexão; ela deveria ser traduzida, e este era seu objetivo: que as pessoas soubessem as palavras que eram ditas. Havia ainda "Sua canção", que se propunha a atender solicitações musicais dos ouvintes que, assim, teriam participação concreta na emissão. E tudo terminava com "Uma canção para rezar", em que uma canção religiosa, que apresentasse ligação com o tema sobre o qual se refletiu, motivasse um momento mais direto de espiritualidade e oração.

Com essa proposta, o programa permanece ainda no ar. Investe na qualidade musical, pois as canções, como se disse, não podem ser comerciais, mas humanas no sentido de fazerem pensar na vida e em valores que a norteiam. Mas não são canções religiosas, são profanas e que são ou foram executadas em todas as rádios. Ao mesmo tempo há diversidade, pois são várias as canções executadas, assim como há diversidade na forma de apresentá-las: uma é para ser traduzida, outra para se conversar a seu respeito, outra para motivar a oração ou a participação do ouvinte, e assim a diversidade pode constituir-se em entretenimento. Através desta "diversão" se busca captar a audiência para que o ouvinte ouça a reflexão que se faz e dela, de alguma forma, participe, e por isso o 
desenvolvimento da reflexão privilegia o caráter vivencial. Ainda mais, há possibilidade de efetivo trabalho de evangelização da cultura em perspectiva missionária, uma vez que a música é elemento importante na manifestação e na formação cultural das pessoas. Parece ser possível fazer com que se veja que a cultura pode se afirmar e se dinamizar pelos valores evangélicos que nela estão ou estarão presentes. Nesse sentido, a emissão pode ter um alcance evangelizador bastante interessante, inclusive por poder dialogar, através das canções, com quem não é religioso ou não confessa a fé.

\section{Para exemplificar}

A análise de uma canção exigirá certa sensibilidade para colocar em evidência as questões importantes que ela comporta e seus elementos de beleza mais significativos. A reflexão teológica, mesmo aquela com interesse pastoral e catequético, é tarefa da inteligência que perscrutará não apenas os elementos da canção, mas o que eles aportam para a teologia e a vivência da fé. Sensibilidade e inteligência serão exigidas para que o programa seja realizado. O exemplo de reflexão apresentado, que agora segue, vale para indicar o realce de aspectos da canção e, igualmente, sua incidência na reflexão teológica.

Resposta ao Tempo, de Cristóvão Bastos e Aldir Blanc.

Batidas na porta da frente é o tempo

Eu bebo um pouquinho pra ter argumento

Mas fico sem jeito, calado, ele ri

Ele zomba do quanto eu chorei

Porque sabe passar e eu não sei

Um dia azul de verão, sinto o vento

Há folhas no meu coração é o tempo

Recordo um amor que perdi, ele ri

Diz que somos iguais, se eu notei

Pois não sabe ficar e eu também não sei.

E gira em volta de mim, sussurra que apaga os caminhos

Que amores terminam no escuro sozinhos.

Respondo que ele aprisiona, eu liberto

Que ele adormece as paixões, eu desperto

E o tempo se rói com inveja de mim

Me vigia querendo aprender

Como eu morro de amor pra tentar reviver 


\author{
No fundo é uma eterna criança \\ que não soube amadurecer \\ Eu posso, ele não vai poder me esquecer.
}

\title{
Leitura
}

Esta canção Resposta ao Tempo, de autoria de Cristóvão Bastos e Aldir Blanc, foi lançada no disco de 1998 de Nana Caymmi, sua intérprete, e foi tema da minissérie Hilda Furacão, da Rede Globo. Aldir Blanc é um dos maiores letristas da música brasileira, e parece realmente inspirado ao compô-la. Apresenta alguém respondendo ao tempo que está como que personificado, alguém que tem consciência do que seja o tempo, do que significa o seu passar e suas marcas na vida das pessoas. Mas este senhor inexorável, o tempo, também pode ter suas fraquezas, pois o tempo não sabe tudo, não é tudo.

A canção começa falando de como se percebe o tempo chegando, como se fosse visita batendo na porta da frente. Ou seja, tempo não passa disfarçado, passa diante de todos e vai deixando suas marcas: rugas, cabelos brancos e todos sabem que o tempo passou. A aparência de juventude se foi, mas nós ficamos. Se ficamos calados diante do passar do tempo parece que ele ri, fazendo pouco e zombando da gente. E zomba porque ele sabe passar, nós não sabemos. Nós ficamos presos a acontecimentos que nos marcaram, a pessoas que fizeram e fazem nossas vidas, ficamos presos a nós mesmos, não conseguimos sair de nós. $\mathrm{O}$ tempo, ele passa, ele só faz isso. A figura do tempo passando é como o outono chegando. $\mathrm{O}$ furor de juventude que quer aproveitar de tudo e vê o tempo escorrendo por entre os dedos, aquele furor cede lugar a uma espécie de maturidade. As lembranças povoam nossas mentes como folhas levadas pelo vento: as situações que foram vividas, os amores que se conheceram... e então nos percebemos como o tempo, que ele não sabe parar, não sabe ficar. A gente também não sabe, porque não se pode ficar nos acontecimentos que se foram. O tempo não fica parado, nem a gente. Nós não ficamos parados no mesmo lugar do mesmo jeito.

O tempo faz brincadeiras com a gente, diz que apaga os caminhos porque traz esquecimento, não os guardamos na memória. É como se tivessem ido, e os amores vividos parece que sempre acabam em solidão. É o tempo rindo da gente. Mas será que a vida é assim?

Depois, a gente experimenta a maturidade; a idade é como experiência acumulada por toda uma vida. Já não mais no afã de 
aproveitar a vida, que é próprio da juventude, nem aquela maturidade iniciante, própria da idade adulta, daqueles que são inquietos e temem a solidão. A experiência de uma vida vivida faz a gente ver o tempo diferente. O tempo guarda as coisas e as pessoas, os acontecimentos e as histórias em momentos passados, mas a gente os liberta porque os transforma em vida que somos nós. E por isso nos lembramos, sorrindo e chorando, das coisas que vivemos e nos fizeram ser o que somos, e assim libertamos nomes, pessoas e coisas quando os lembramos com afeto, libertamos os acontecimentos e as histórias quando as contamos para os outros.

O tempo apaga as paixões, porque traz o esquecimento. Mas o despertamos porque as transformamos em vida, em força de viver. Então o tempo, aquele senhor, começa a ter inveja da gente, querendo aprender esta capacidade de amar que nós temos, mas ele não tem. No fundo, diz a canção, o tempo é como uma criança que não sabe amadurecer. Fica sempre naquela infantilidade de passar, de mudar, de querer outra coisa, sem capacidade de fincar raízes. Ele sempre como que ri de nós pelo que nos faz sofrer; e se podemos esquecer-nos do tempo, não percebendo como ele passa, a gente marca a história, e por isso o tempo não vai poder nos esquecer, já que fazemos parte do tempo, da história.

Vista assim, a canção é uma bela reflexão sobre a natureza do tempo: o que ele produz em nós, como nos marca, como condiciona nossa vida. E nos faz perceber os mecanismos que podemos usar que fazem o tempo ser vencido: as lembranças que atualizam presenças que se foram; o amadurecimento que nos faz ficar com as coisas boas da vida, esquecendo, ou passando por cima, das dores e das desilusões que vivemos. Aprendemos a ser com o tempo, aprendemos não apenas a viver, mas a ser mais conforme o tempo passa. Aprendemos ser nós mesmos, valorizar aquilo que realmente importa. É preciso aprender a viver no tempo e com ele, pois ele não nos domina, já que o marcamos mais do que ele nos marca pelas coisas que fazemos e pelo que podemos influir na história que vamos construindo para nós, para a sociedade e para o mundo inteiro.

\section{Teologia}

Para aprofundar um pouco a reflexão em termos de fé, é necessário pensar em algumas coisas que são básicas, mas que, normalmente em ambiente religioso, não se pensa, ou então se acha que não é bom. É 
preciso lembrar, em primeiro lugar, que o tempo também é criatura de Deus. Não existe tempo que não tenha sido criado. Deus vive fora do tempo, é atemporal, dele falamos em eternidade. Ele não está submetido ao tempo, que é sua criatura submetida, então, a ele. Por isso o salmista pode dizer que "mil anos são como o dia de ontem que se foi". O tempo é criação de Deus, é invenção de Deus.

A segunda coisa a lembrar é de que o tempo é o ambiente de desenvolvimento da vida humana. Ao ser humano foi dado tudo o que foi criado, inclusive o tempo. Não se pode pensar no humano fora do tempo. E nisso o ser humano é diferente de Deus, completamente diferente. O ser humano está submetido ao tempo de tal maneira que esta é sua condição existencial, ou seja, não sabe viver fora do tempo, não há humanidade fora do tempo.

Outro elemento a lembrar é que o tempo, para o humano, é história. Tempo não é o que o relógio marca, não são segundos que passam depressa. O tempo é história e tudo o que é humano é histórico, sobre todas as coisas se podem contar histórias; tudo na vida do humano é processo. Tempo e história lembram esta ideia de processo, de estar em desenvolvimento, de ir sendo, de se construir de maneira histórica.

E isso traz algumas consequências muito bonitas para a existência humana, inclusive aos olhos da fé. A primeira delas é que não se está preso no ontem; a história continua, as pessoas continuam existindo, evoluindo, aprendendo, continuam sendo. E podem continuar assim vida afora. É como dizer que nós não estamos prontos, não estamos terminados ainda. Não somos tudo aquilo que podemos ser, que precisamos ser, que somos chamados a ser. Podemos ser mais, podemos ser melhores. Não fomos criados perfeitos e acabados, mas em processo. É preciso nos construir, é possível nos construir. Não importa o tempo que tenhamos vivido, somos sempre seres inacabados, incompletos, em processo de desenvolvimento, inclusive em processo de conversão.

Outra consequência é que existir é fazer história. Não é apenas o mundo que nos marca, nós também marcamos o mundo. O que quer que aconteça amanhã ou depois de amanhã, deixamos nossa marca no mundo para sempre. Nossos nomes estão escritos na história; há pessoas que conhecemos e que continuarão a existir depois de nós, que continuarão falando de nós. E quando não formos mais conhecidos, ainda assim teremos marcado o mundo com nossa presença e nosso jeito de ser.

E não se pode esquecer que o tempo passa. Não importa o que aconteça, ele passa, cura feridas e traz esquecimento, bálsamo para o 
sofrimento. É possível guardar as lembranças boas e torná-las presentes como se fossem novamente vividas na memória. Pode-se esquecer o que fez sofrer, o que machucou, não é necessário trazer isso constantemente presente na vida. $\mathrm{O}$ que se carrega são cicatrizes, mas cicatrizes não doem mais, feridas doem. E feridas o tempo cura, liberta. Viver o hoje sem carregar o peso do ontem, apenas o leve fardo das lembranças.

Ainda há a realidade da eternidade para ser pensada. A eternidade é a salvação do tempo, o Reino de Deus é a salvação da história, não sua negação. Salvação de Deus é plenificação do humano, e não negação do que se é ou do que se foi. A eternidade não é um castigo de esquecimento, exatamente porque não é tempo. O tempo apaga lembranças, a eternidade as plenifica. Por isso a salvação de Deus não é ir contra aquilo que somos e fomos, mas a completude do que fomos e somos.

Se somos criados seres inacabados, a eternidade nos completa. Não porque proporciona um estado permanente de determinada situação vivida, porque a eternidade não tem duração. Talvez tenha intensidade, aquela do amor de Deus. Como não podemos pensar como seres humanos fora do tempo, imaginamos a eternidade como se fosse tempo, achando que é duração infinita. Daí aquele "para sempre" dos finais felizes: foram felizes para sempre. Acaba a história, mas como que continua uma duração. A eternidade não obedece a essas categorias, até porque todos nós vivemos, alguma vez, como que "um momento de eternidade", um momento tão intenso que era como se fosse perfeito, completo, "para sempre". Não temos uma linguagem adequada para falar da eternidade e por isso falamos sempre de tempo. Mesmo em tempo no purgatório, em tempo das indulgências e coisas assim. Isso está mais para uma maneira de falar porque não temos como nos referir àquilo que não sabemos exprimir, já que somos seres temporais. Mas cremos na completude, em um "novo tempo". Quando falamos em fim dos tempos, estamos falando de completude, de estarmos completos, de sermos completos pela realização da salvação de Deus.

Duas outras coisas ainda. Uma delas é lembrar que já que somos seres temporais, que não sabem viver fora do tempo, então será preciso valorizar o tempo que vivemos, pois ele tem importância, sim. Tudo o que fazemos no tempo e com o tempo tem importância. As coisas temporais também importam, mesmo se são passageiras. Nós as tratamos como passageiras, mas como estão no nosso lugar existencial não são desprovidas de importância. Se vivemos agora pensando apenas na eternidade, não nos construímos como pessoas, não entramos em 
processo e não haverá o que completar. Se vivemos na terra pensando que nosso lugar é o céu, corremos o risco de não viver aqui as condições para aceder à eternidade completa que Deus quer partilhar conosco. $\mathrm{O}$ tempo que vivemos é onde se pode sentir o gosto da salvação que Deus nos promete; o tempo é lugar de salvação porque aqui Deus nos alcança: ele penetrou o tempo, o eterno entrou no tempo e, assim, o tempo pode ser salvo e eternizado.

Finalmente, é preciso entender que nossa fé fala de uma promessa, o tempo do futuro, para onde nos voltamos. Não somos daqueles que vivem olhando o passado, mas o futuro. Deus nos prometeu salvação, completude, não retorno. Seremos completos pelo amor de Deus, por sua salvação, naquele novo tempo em que seremos completados pela recordação de Deus. Ele se lembrará de nós e no seu abraço de Pai, tão intenso, o tempo será eternidade.

\section{Conclusão}

O exemplo acima mostra pequena reflexão realizada, em horizonte teológico-pastoral, a partir de canções da música brasileira e veiculadas em programa radiofônico. Ao menos três pontos parecem evidentes a partir do que foi mostrado, e vale a pena destacá-los.

O primeiro é o da possibilidade de aproximar a reflexão teológica do universo das canções populares pelos mesmos procedimentos que aproximam teologia e literatura. Que tal aproximação se dê pelas letras das canções parece elementar. $\mathrm{O}$ segundo aponta para a variedade de métodos que podem ser utilizados na aproximação da teologia com o universo das canções. Por fim, a relevância da reflexão pastoral a partir do horizonte da cultura popular. Não que a teologia em sentido estrito não possa desenvolver-se a partir daí, ao contrário; mas a questão pastoral se coloca diante dos olhos de maneira inevitável, e a proposta de emissão radiofônica aponta para a popularização de uma reflexão que faz pensar e promove o agir.

\section{Referências}

AMARAL, Daniel do. Música e teologia. São Paulo: Fonte Editorial, 2013.

BOAS, Alex Villas. Teologia e Poesia. Sorocaba: Crearte, 2011.

CALVANI, Carlos Eduardo Brandão. Teologia e MPB. São Paulo: Loyola, 1998. 
CNBB. A música litúrgica no Brasil. São Paulo: Paulus, 2002. 4. ed. (Estudos da CNBB, 79).

HERRERA, Paula Miranda. La poesía de Violeta Parra. Santiago: Editorial Cuarto Propio, 2013.

KUSCHEL. Karl-Josef. Os escritores e as escrituras. São Paulo: Loyola, 1999.

MAGALHÃES, Antonio. Deus no espelho das palavras. São Paulo: Paulinas, 2000.

MANZATTO, Antonio. Pequeno panorama de teologia e literatura. In: VILHENA, Maria Ângela; MARIANI, Ceci Baptista. Teologia e Arte. São Paulo: Paulinas. 2010. p. 87-98.

. Teologia e Literatura. São Paulo: Loyola, 1994.

PALUMBO, Cecília Avenatti de (Coord.). La libertad del Espiritu. Buenos Aires: Ágape Libros, 2014.

RICOEUR, Paul. Du texte à l'action. Essais d'herméneutique II. Paris: Seuil, 1986.

TILLICH, Paul. Teologia Sistemática. São Leopoldo: Sinodal, 2005.

Recebido: 24/05/2014

Avaliado: 12/09/2014 